1 Fergus M Guppy ${ }^{\mathrm{a} *}$, Joanne A Wallace ${ }^{\mathrm{b}}$ and Rhys Thatcher ${ }^{\mathrm{b}}$

$2{ }^{a}$ Stress, Ageing and Disease Research Group, School of Pharmacy and

3 Biomolecular Sciences, University of Brighton, Brighton, UK; ${ }^{b}$ Institute of

4 Biological, Environmental and Rural Sciences, Aberystwyth University,

5 Aberystwyth, UK

$6 *$ Corresponding Author

$7 \quad$ Email: F.Guppy@brighton.ac.uk

$8 \quad$ Tel: $+44(0) 1273641631$ 


\section{Six weeks of sprint interval training improves body composition in}

\section{1 healthy young males}

Exercise plays a key role in improving body composition and bone health.

This study aims to look at the effects of a sprint interval training (SIT) programme, on markers of skeletal health and body composition measured by daul-energy x-ray absorptiometry (DXA). Twenty-eight participants $\left(24.4 \pm 6.7 \mathrm{y} ; 1.77 \pm 0.09 \mathrm{~m} ; 79.0 \pm 14.5 \mathrm{~kg} ; 25.0 \pm 2.8 \mathrm{~kg} \bullet \mathrm{m}^{-2}\right)$ were randomly assigned, into either the SIT or control condition. All participants made a single fasted visit to the laboratory, pre-and post a 6 week SIT intervention, where they underwent a whole body, proximal femur and lumbar spine DXA scan. SIT caused significant reductions in sub-total ($1.08 \mathrm{~kg})$ and lower $\operatorname{limb}(-0.50 \mathrm{~kg})$ fat mass, as well as on upper- $(-1.26 \%)$ and lower-limb (-1.70\%) percentage fat mass compared with non-exercising controls $(0.26,0.00 \mathrm{~kg} ;-0.15,-0.28 \%)$. There were no significant changes in any bone measures, but trends were observed for differences in femoral neck BMD (1.75\%), total proximal femur BMC (5.79\%) and area (4.81\%) following SIT compared to the control group $(-1.51,0.05,0.36 \%)$. This study showed that SIT is a potent method of reducing fat mass, as well as a potential as a method for improving bone mass.

\section{$\underline{\text { 1. Introduction }}$}

Sprint interval training (SIT) and high-intensity interval training (HIIT)

32 have emerged over the last decade as extremely potent training methods (Gillen \&

33 Gibala, 2014). These two methods, classified by Weston et. al. (2014), utilise

34 repeated bouts of high-intensity exercise, interspersed with recovery, either 
35 between $80-100 \%$ peak heart rate (HIIT) or above $\mathrm{VO}_{2} \max$ (SIT). Although, these

36 two intervention styles involve repeated anaerobic exercise, both HIIT and SIT have

37 been shown to have performance and health benefits that are traditionally seen

38 following long duration endurance training. These adaptations include, but are not

39 limited to, increased endurance capacity (Burgomaster et al., 2008), increased

40 mitochondrial enzyme action (Burgomaster et al., 2005; 2006; 2007; 2008; Gibala

41 et al., 2006), improvements in insulin sensitivity (Babraj et al., 2009; Metcalfe,

42 Babraj, Fawkner, \& Vollaard, 2011), skeletal muscle protein content (Burgomaster

43 et al., 2007), as well as in fat metabolism (Babraj et al., 2009; Metcalfe et al., 2011;

44 Sim, Wallman, Fairchild, \& Guelfi, 2013). These positive outcomes suggest HIIT

45 and SIT interventions have a role to play in providing individuals with alternative

46 exercise modalities to improve both health and performance, with a relatively short

47 time commitment.

48 Measuring changes in body composition due to any intervention is

49 important in both clinical and athletic populations (Guppy \& Wallace, 2012), and

50 has been looked at in SIT interventions, there is limited evidence examining SIT or

51 the effect of SIT on the gold standard three-compartment model of body

52 composition measured by DXA (Wang, Pierson, \& Heymsfield, 1992). The

53 majority of studies show a reduction $(0.72-2.57 \%)$ in percentage fat mass following

54 SIT interventions (Boer et al., 2014; Gillen, et al., 2013; Shing, et al., 2013; Terada

55 et al., 2013; Verney, et al., 2006). The studies that utilise a three compartment model

56 report reductions in both trunk (2.5\%) and lower limb (1.6\%) fat mass after a 12 -

57 week intervention (Terada et al., 2013), and increased lower limb lean mass (0.6

$58 \mathrm{~kg}$ ) (Gillen et al., 2013) following 6 weeks of SIT. 
The three-compartment model of body composition has a distinct

60 advantage over other models as it allows for the separation of fat-free mass into

61 lean- and bone mass (Wang et al., 1992). This advantage allows for the inclusion

62 of changes in bone material to be made alongside changes in fat- and lean-mass.

63 Strain has been shown to play a critical role in bone mass development, with Frost

64 (1987) proposing the Mechanostat as a likely method of adaptation of bone material

65 to loads placed upon it. The importance of strain was further illustrated by Skerry

66 (2006), who suggests that strain stimulus, number of loading cycles and the amount

67 of rest between load cycles all play a role in skeletal adaptation to mechanical

68 loading, described by Skerry (2006) as the Customary Strain Stimulus (CSS). This

69 process of repeated load intermitted with periods of rest is the definition of both

70 HIIT and SIT (Weston et al., 2014), therefore, these methods may provide a

71 mechanism for achieving adaptations to the skeleton. There has been limited

72 investigation into the role of either HIIT or SIT on the skeleton, with only a single

73 study examining the effects of HIIT on bio-markers of bone turnover (Mezil et al.,

74 2015). This study showed that a single session of high-intensity low impact activity

75 increased osteoblast responsiveness via increased osteoprotegerin (OPG) and bone

76 alkalkine phosphatase (BAP), which are both responsible for primarily responsible

77 for regulating osteoclast activity (Datta, et al., 2008; Kwan Tat, et al., 2004). This

78 study also showed increased inflammatory cytokine response which (Mezil et al.,

79 2015) suggests are associated with increased osteoclast activity differentiation by

80 promoting production of receptor activated of NF- $\kappa B$ ligand (RANKL) and OPG

81 with a net increase in RANKL (Kwan Tat et al., 2004).

82 To address the lack of detailed body composition data following SIT

83 intervention, the main aim of this study was to investigate the effects of a 6-week 
84 SIT cycling programme on body composition measured using dual-energy x-ray

85 absorptiometry (DXA). The authors hypothesised that SIT will result in increased

86 lean mass in the lower limbs, whilst reducing whole body fat mass. To examine the

87 effect of a SIT programme on bone adaptation, a secondary aim of this study was

88 to examine the effect of a SIT intervention on bone mass measured in the proximal

89 femur and lumbar spine, in a sub-group of participants within the study.

\section{2. Methods}

\section{$91 \quad 2.1$ Experimental Approach to the Problem}

92 A randomized controlled trial was conducted to examine the effects of a 6-

93 week SIT on a 3-compartment model of body composition, as well as bone mass at

94 the lumbar spine and proximal femur. Participants made two visits to the laboratory;

95 pre and post a 6-week SIT intervention. Each visit was made following a 10-hour

96 overnight fast and included three whole body dual-energy $\mathrm{x}$-ray absorptiometry

97 (DXA) scans.

\subsection{Participants}

99 Twenty-eight male participants $($ Age $=24.4 \pm 6.7 \mathrm{y}$, Height $=1.77 \pm 0.09 \mathrm{~m}$,

100 Mass $=79.0 \pm 14.5 \mathrm{~kg}, \mathrm{BMI}=25.0 \pm \mathrm{kg} \bullet \mathrm{m}^{-2}$ ) volunteered to take part in this study.

101 Ethical approval was sought and gained from the University Research Ethics

102 Committee, and complied with the World Medical Association Declaration of

103 Helsinki, and the ethical standards described by Harriss \& Atkinson (2009).

104 Participants were randomly allocated in a blind manner by a member of the research

105 team not involved in data collection into either the SIT or a control group. There

106 were no significant differences at baseline in age (years) $\left(t_{(1-26)}=-0.014, p=0.989\right)$, 
107 height $(\mathrm{m})\left(\mathrm{t}_{(1-26)}=-0.536, \mathrm{p}=0.596\right)$, mass $(\mathrm{kg})\left(\mathrm{t}_{(1-26)}=-0.774, \mathrm{p}=0.446\right)$ or BMI

$108\left(\mathrm{~kg} \cdot \mathrm{m}^{-2}\right)\left(\mathrm{t}_{(1-26)}=-0.321, \mathrm{p}=0.751\right)$ between the groups. Activity levels out-with the

109 study were measured using the short form of the International Physical Activity

110 Questionnaire in a subsection of 18 participants in both the exercise $(n=9)$ and

111 control $(\mathrm{n}=9)$ groups. A 2-way analysis of variance showed no difference in activity

112 levels outwith the study due to training $\left(\mathrm{F}_{(1-29)}=0.194, \mathrm{p}=0.663\right)$ or time $\left(\mathrm{F}_{(1-}\right.$

$113{ }_{29}=0.216, \mathrm{p}=0.645$ ) with no interaction between these variables $\mathrm{F}_{(1-29)}=0.068$, $114 \mathrm{p}=0.797)$.

\section{$115 \quad 2.3$ Experimental Procedures}

\section{2.3.1 Body Composition Assessment}

117 Total and regional body composition was estimated by DXA (Discovery A,

118 Hologic Inc., Massachusetts, USA), with images analysed using Hologic Apex

119 software (Apex v3.2.1, Hologic Inc., Bedford, MA, USA) for the calculation of lean

120 and fat mass $(\mathrm{kg})$ as well as percentage fat mass. The scanner was calibrated before

121 each use by bone phantom (Hologic Inc.) for quality assurances, and no evidence

122 of machine drift appeared during this study. Unpublished work by this laboratory

123 showed greater repeatability when left and right limbs were combined, therefore

124 this approach is adopted in the current study. Due to the inbuilt analysis assumptions

125 regarding the measurement of head composition, sub-total data (total - head region)

126 will be reported in this study. Precision of operator repeated measurements ranged

127 from $0.26-1.69 \%$ for total mass, $1.36-2.78 \%$ for fat mass and $0.77-1.90 \%$ for lean 128 mass. 
Areal Bone Mineral Density $\left(\mathrm{BMD}, \mathrm{g} \bullet \mathrm{cm}^{-2}\right)$, Bone Mineral Content $(\mathrm{BMC}$,

$131 \mathrm{~g})$ and bone mineral area $\left(\mathrm{cm}^{2}\right)$ was measured in the lumbar spine (L1-L4) and the

132 left proximal femur by DXA and analysis was conducted using the preinstalled 133 machine software. Total lumbar spine, proximal femur, femoral neck and Ward's

134 triangle were analysed separately, with all scanning and analysis conducted by the

135 same operator, with precision of repeated measurements ranging from 1.51-3.15\%

136 for BMD, 3.46-8.66\% for BMC and $1.87-8.08 \%$ for bone mineral area.

\subsubsection{Sprint Interval Training Programme}

The SIT group undertook 18 supervised SIT sessions over a 6-week period,

140 with 1-2 days recovery between sessions. SIT consisted of 4-6 repeated 30-s

141 maximal cycling efforts against a resistance equivalent to $7.5 \%$ body mass on a

142 cycle ergometer (Monark, 874E, Varberg, Sweden). Participants completed four

143 sprints per session in weeks 1 and 2, five sprints in weeks 3 and 4 and six sprints in

144 weeks 5 and 6, based on protocols of similar (Burgomaster et al., 2007) and 2-weeks

145 (Babraj et al., 2009; Burgomaster et al., 2005; 2006; 2008; Gibala et al., 2006)

146 duration. Exercise sessions commenced with a 5-minute warm up at a nominal

147 resistance (approximately $60 \mathrm{~W}$ ) prior to the first sprint with each of the sprints

148 separated by a 4-minute recovery period. Participants were encouraged to remain

149 on the ergometer during recovery periods and to maintain a low pedal cadence. The

150 total time commitment ranged from 19 to 28 minutes, with the sprint exercise

151 totaling 2-3 minutes per session. 
153 Data were analysed using a factorial analysis of covariance (ANCOVA),

154 with the baseline value used as a covariate to adjust post-test values relative to the 155 baseline values. This approach is deemed to show the greatest statistical efficiency

156 (Vickers, 2001). Alpha level was set at 0.05 and data is presented as mean \pm 157 standard error (SEM).

158 3. Results

\subsection{Body Composition}

Total body mass was unchanged as a result of SIT (SIT; $80 \pm 4-\mathrm{v}-81 \pm 5$,

$161 \mathrm{CON} ; 76 \pm 6-\mathrm{v}-77 \pm 6 \mathrm{~kg} ; \mathrm{p}<0.05)$. Dual energy $\mathrm{x}$-ray absorptiometry revealed

162 reduced sub-total and lower limb fat mass (Table 1, Figure 1; $<<0.05$ ), but no

163 significant reduction in fat mass of the upper limbs (Table 1) following SIT

164 intervention. There was also reduced percent fat in both the upper and lower limbs

165 (Table 2, $\mathrm{p}<0.05$ ) but not in sub-total percentage fat. There were no significant 166 changes in either lean or total mass due to SIT (Table 1).

167 Table 1 Changes in Body Composition

***TABLE 1 SOMEWHERE HERE***

171 Figure 1 Effect of 6-weeks of sprint interval training (SIT) or no training (Control)

172 on change in fat mass $(\mathrm{kg})$ of the upper limbs, trunk, lower limbs and sub-total

173 regions measured by DXA. Circles/squares show individual change and horizontal 
174 bars show mean group change from baseline. */\# denotes different from control

175 condition $(* \mathrm{p}<0.05 ; \# \mathrm{p}<0.1)$.

\section{$176 \quad 3.2$ Bone Mass}

177 SIT led to near significant increases in BMD at the femoral neck $(1.75 \%$

178 PRE: $\left.1.03 \pm 0.21-\mathrm{v}-1.05 \pm 0.19 \mathrm{~g} \bullet \mathrm{cm}^{-2}, \mathrm{p}=0.059\right)$, total hip area $(4.81 \% ; 44.16 \pm$

$\left.1796.47-\mathrm{v}-46.17 \pm 6.25 \mathrm{~cm}^{-2}, \mathrm{p}=0.083\right)$, and total hip BMC $(5.79 \% ; 51.84 \pm 15.13-\mathrm{v}-$

$18054.35 \pm 14.25, p=0.059$, Figure 2$)$, compared with non-exercising controls $(-1.52$,

$181 \quad 0.36 \& 0.05 \%)$. There were no other changes in either bone density, content or area

182 as can be seen in Table 2.

184 Figure 2. Percentage change from baseline in Total Proximal Femur (Total) bone 185 mineral density (BMD), bone mineral content (BMC), and Area as well as Femoral 186 Neck (FN) and Wards triangle (Wards) BMD following 6 weeks SIT. 187 Circles/squares show individual change and horizontal bars show mean group 188 change from baseline. * denotes different from control group $(\mathrm{p}<0.1)$.

189 Table 2. Changes in Bone Mineral Content, Density and Area measured by DXA 190 following 6 weeks SIT. ***TABLE 2 SOMEWHERE HERE***

\section{4. Discussion}

\subsection{Body Composition}

This study aimed to examine the effects of 6-weeks SIT on a 3-compartment

195 model of body composition. This study showed reductions in sub-total $(1.08 \mathrm{~kg})$, 
196 and lower limb $(0.5 \mathrm{~kg})$ fat mass, with these reductions being of similar magnitude

197 to those previously shown (Gillen et al., 2013; Smith et al., 2009). There was also

198 a non-significant increase in sub-total lean mass $(0.41 \mathrm{~kg})$ of similar magnitude to

199 that reported by Gillen et. al. (2013) (0.4 kg). These changes in body composition

200 occurred without subsequent reductions in sub-total mass, reinforcing the use of

201 more complex measures of body composition assessment rather than simply using

202 mass alone when assessing the efficacy of training and/or dietary interventions on

203 body composition and mass.

204 The potential mechanisms behind reduced fat mass in response to SIT 205 include changes in fat oxidation, both during and post exercise, as well as alterations

206 in appetite and energy intake (Deighton \& Stensel, 2014; Sim et al., 2013). These

207 changes, particularly in appetite, have also shown that supramaximal interval 208 training may be more effective at inducing changes in body composition via 209 appetite regulation than MICT (Sim, et al., 2015). These alterations in appetite 210 regulation appear alongside reductions in energy intake (Sim et al., 2013) and

211 increased energy expenditure (Hazell, et al., 2012). This increased energy 212 expenditure could be due to increased glycogen resynthesis, dissipation of blood 213 lactate (Boutcher, 2011) or increased catecholamine induced metabolism and 214 lipolysis (Bracken, Linnane, \& Brooks, 2009), as well the thermic effect of exercise 215 or increased muscle protein turnover (Hazell et al., 2012).

\section{$217 \quad 4.2$ Bone Mass}

218 The major mechanisms behind skeletal adaptation to mechanical load are

219 through changes in lean mass and increased strain placed upon the skeleton.

220 However, in this study there were no observed changes in lean mass, with only 
221 reductions seen in fat mass, suggesting that increased strain alone is driving the

222 changes seen in this study. The literature has previously suggested that weight-

223 bearing exercise is key to this change, with non-weight bearing activities such as

224 rowing and swimming often having a detrimental effect on bone (Gómez-Bruton,

225 et al., 2013; Olmedillas, et al., 2012). However, this study has shown near

226 significant increases in femoral neck BMD (3.25\% -v- controls), total hip area of

227 bone material (4.45\%), and total hip BMC (5.74\%) in a non-weight bearing activity.

228 The changes seen in this study are of greater magnitude to those seen in studies of

22924 (Maddalozzo \& Snow, 2000) and 52 weeks (Vainionpää, et al., 2004) and of

230 similar magnitude to results reported after 48 weeks of ground reaction force

231 inducing exercise by Kohrt et. al. (1997). These near clinical changes in BMD after

232 only 6-weeks are potentially important as researchers suggest that a minimum of

233 24-weeks are required to induce skeletal changes (Kelley, Kelley, \& Kohrt, 2013a;

234 2013b). The rapid changes observed in this study show that SIT has the potential

235 for increasing BMD over a much shorter time frame than traditional modalitites for

236 improving BMD due to the supramaximal nature of this exercise type.

237 Although the observed changes fall short of reaching statistical significance,

238 the site specific nature points to the likelihood of the Mechanostat as the mechanism

239 behind any adaptation. Bone adaptation occurs when it is loaded, when it becomes

240 deformed, or under strain (ratio of change in length divided by original length)

241 (Skerry, 2006). Due to the high intensity nature of SIT the CSS is potentially being

242 exceeded, therefore causing adaptations to the site being loaded. As cycling is a

243 predominantly lower limb activity, with limited whole body involvement, changes

244 would only be expected at the proximal femur, as seen in this study, in addition to

245 the lower limbs. Although SIT also induces metabolic adaptations that could 
246 influence bone metabolism and therefore density, including changes in insulin

247 action (Babraj et al., 2009), it is unlikely that these changes are the major influence

248 on the skeleton. This is shown by the lack of change in the lumbar spine (Table 3),

249 which if bone were being altered via systemic rather than local factors would show

250 some adaptation.

251 The frequency of stimulation has been suggested as important when

252 examining improvements in bone mass induced by loading, as shown by low 253 frequency stimulation inducing the proliferation of osteoblasts in formation and

254 remodelling (Scott, et al., 2008). Therefore, with frequency playing a crucial role,

255 more frequent, shorter sprints may play a similar role in causing bone adaptations,

256 and are therefore an interesting avenue for further research.

\subsection{Limitations and Future Directions}

Both SIT and SIT have limitations that need to be explored, particularly the

259 achievability of this type of exercise in clinical populations. The SIT protocol used

260 in this study is based upon a Wingate test, with the resistance set at $7.5 \%$ of body

261 mass, which although achievable in non-clinical populations, is this the case in

262 clinical populations. Changes in body composition are often required in disease

263 states such as type-2 diabetes mellitus, and specifically required in obesity. As

264 obese individuals will, and T2DM patients often do, have a large amount of

265 unfunctional, fat mass (Strasser, 2012), 7.5\% of body mass may make this

266 resistance unrealistic in clinical populations. Further work is needed to establish the

267 most effective protocol that balances between health benefits, and the ability of the

268 patient to undertake the intervention. The exclusion of unfunctional fat mass from

269 the calculation of resistance may provide a more realistic intensity of exercise for

270 clinical populations. In addition future studies, should measure energy intake and 
271 expenditure, as well as markers of appetitete regulation and other factors that

272 influence fat loss. This would allow determination of what mechanisms are driving

273 fat mass loss and the lack of lean mass gains.

274 When examining bone mass, it has been suggested that the frequency of the

275 stimulation is important regarding the improvement of bone tissue. This has been

276 shown with low frequency stimulation of osteoblasts playing a role in the

277 proliferation of these key cells in formation and remodelling (Scott et al., 2008).

278 Therefore, with frequency playing a crucial role, would more frequent, shorter

279 sprints play a similar role in causing bone adaptations, following SIT. The

280 effectiveness of this method in clinical populations is dependent on researchers

281 identifying the optimum level of intervention.

\subsection{Conclusion}

In conclusion, although these findings did not reach statistical significance,

285 this study illustrates the potential that HIIT may have at maintaining or improving 286 skeletal health. Further studies are needed exploring how HIIT can induce changes

287 in bone material. The current trend in the literature is to reduce the time 288 commitment of this form of exercise in order to establish the lowest volume of 289 training needed (Metcalfe, et al., 2016; Ruffino et al., 2017), therefore trying to 290 strike a balance between the positive outcomes associated with HIIT and the

291 feasibility of this intervention in the populations that need it most. However, this 292 approach may not be beneficial when considering bone health, but further 293 investigation is needed to establish the effectiveness of this intervention at 294 improving bone mass. 
297 The authors would like to thank Joanna Worthington and Alex Moss for their

298 assistance in running the training sessions.

\section{References}

300 Babraj, J. A., Vollaard, N. B., Keast, C., Guppy, F. M., Cottrell, G., \& Timmons, J. 301 A. (2009). Extremely short duration high intensity interval training 302 substantially improves insulin action in young healthy males. BMC Endocrine 303 Disorders, 9(1), 596-8. http://doi.org/10.1186/1472-6823-9-3

304 Boer, P.-H., Meeus, M., Terblanche, E., Rombaut, L., Wandele, I. D., Hermans, 305 L., et al. (2014). The influence of sprint interval training on body 306 composition, physical and metabolic fitness in adolescents and young adults 307 with intellectual disability: a randomized controlled trial. Clinical 308 Rehabilitation, 28(3), 221-231. http://doi.org/10.1177/0269215513498609

309 Boutcher, S. H. (2011). High-Intensity Intermittent Exercise and Fat Loss. Journal 310 of Obesity, 2011(4), 1-10. http://doi.org/10.1155/2011/868305

311 Bracken, R. M., Linnane, D. M., \& Brooks, S. (2009). Plasma catecholamine and 312 nephrine responses to brief intermittent maximal intensity exercise. Amino 313 Acids, 36(2), 209-217. http://doi.org/10.1007/s00726-008-0049-2

314 Burgomaster, K. A., Cermak, N. M., Phillips, S. M., Benton, C. R., Bonen, A., \& 315 Gibala, M. J. (2007). Divergent response of metabolite transport proteins in 316 human skeletal muscle after sprint interval training and detraining. AJP: 317 Regulatory, Integrative and Comparative Physiology, 292(5), R1970-R1976. 318 http://doi.org/10.1152/ajpregu.00503.2006

319 Burgomaster, K. A., Heigenhauser, G. J. F., \& Gibala, M. J. (2006). Effect of 320 short-term sprint interval training on human skeletal muscle carbohydrate 
metabolism during exercise and time-trial performance. Journal of Applied Physiology, 100(6), 2041-2047. http://doi.org/10.1152/japplphysiol.01220.2005

324 Burgomaster, K. A., Howarth, K. R., Phillips, S. M., Rakobowchuk, M.,

325 MacDonald, M. J., McGee, S. L., \& Gibala, M. J. (2008). Similar metabolic 326 adaptations during exercise after low volume sprint interval and traditional 327 endurance training in humans. The Journal of Physiology, 586(1), 151-160. http://doi.org/10.1113/jphysiol.2007.142109

329 Burgomaster, K. A., Hughes, S. C., Heigenhauser, G. J. F., Bradwell, S. N., \& 330 Gibala, M. J. (2005). Six sessions of sprint interval training increases muscle 331 oxidative potential and cycle endurance capacity in humans. Journal of 332 Applied Physiology, 98(6), 1985-1990.

333 http://doi.org/10.1152/japplphysiol.01095.2004

334 Datta, H. K., Ng, W. F., Walker, J. A., Tuck, S. P., \& Varanasi, S. S. (2008). The 335 cell biology of bone metabolism. Journal of Clinical Pathology, 61(5), 577$336 \quad$ 587. http://doi.org/10.1136/jcp.2007.048868

337 Deighton, K., \& Stensel, D. J. (2014). Creating an acute energy deficit without 338 stimulating compensatory increases in appetite: is there an optimal exercise 339 protocol? Proceedings of the Nutrition Society, 73(2), 352-358.

$340 \quad$ http://doi.org/10.1017/S002966511400007X

341 Frost, H. M. (1987). Bone "mass" and the "mechanostat": A proposal. The 342 Anatomical Record, 219(1), 1-9. http://doi.org/10.1002/ar.1092190104

343 Gibala, M. J., Little, J. P., Van Essen, M., Wilkin, G. P., Burgomaster, K. A., 344 Safdar, A., et al. (2006). Short-term sprint interval versustraditional endurance 345 training: similar initial adaptations in human skeletal muscle and exercise 
performance. The Journal of Physiology, 575(3), 901-911. http://doi.org/10.1113/jphysiol.2006.112094

348 Gillen, J. B., \& Gibala, M. J. (2014). Is high-intensity interval training a time-

349 efficient exercise strategy to improve health and fitness? Applied Physiology,

$350 \quad$ Nutrition, and Metabolism, 39(3), 409-412. http://doi.org/10.1139/apnm-

$351 \quad 2013-0187$

352 Gillen, J. B., Percival, M. E., Ludzki, A., Tarnopolsky, M. A., \& Gibala, M. J.

353 (2013). Interval training in the fed or fasted state improves body composition

354 and muscle oxidative capacity in overweight women. Obesity, 21(11), 2249-

$355 \quad 2255$. http://doi.org/10.1002/oby.20379

356 Gómez-Bruton, A., González-Agüero, A., Gómez-Cabello, A., Casajus, J. A., \&

357 Vicente-Rodríguez, G. (2013). Is Bone Tissue Really Affected by Swimming?

$358 \quad$ A Systematic Review. PLoS ONE, 8(8), e70119-25.

359 http://doi.org/10.1371/journal.pone.0070119

360 Guppy, F. M., \& Wallace, J. A. (2012). The measurement of body composition in 361 an athletic population: The importance of DXA. Measurement and Control, 362 45(6), 177-181. http://doi.org/10.1177/002029401204500603

363 Harriss, D. J., \& Atkinson, G. (2009). International Journal of Sports Medicine 364 ethical standards in sport and exercise science research. International Journal 365 of Sports Medicine, 30(10), 701-702. http://doi.org/10.1055/s-0029-1237378

366 Hazell, T. J., Olver, T. D., Hamilton, C. D., \& Lemon P, W. R. (2012). Two

367 minutes of sprint-interval exercise elicits 24-hr oxygen consumption similar to 368 that of 30 min of continuous endurance exercise. International Journal of 369 Sport Nutrition and Exercise Metabolism, 22(4), 276-283.

370 Kelley, G. A., Kelley, K. S., \& Kohrt, W. M. (2013a). Exercise and bone mineral 
density in men: a meta-analysis of randomized controlled trials. Bone, 53(1), 103-111. http://doi.org/10.1016/j.bone.2012.11.031

373 Kelley, G. A., Kelley, K. S., \& Kohrt, W. M. (2013b). Exercise and Bone Mineral

374 Density in Premenopausal Women: A Meta-Analysis of Randomized

375 Controlled Trials. International Journal of Endocrinology, 2013(4), 1-16.

$376 \quad$ http://doi.org/10.1155/2013/741639

377 Kohrt, W. M., Ehsani, A. A., \& Birge, S. J. (1997). Effects of Exercise Involving

378 Predominantly Either Joint-Reaction or Ground-Reaction Forces on Bone

379 Mineral Density in Older Women. Journal of Bone and Mineral Research, $380 \quad$ 12(8), 1253-1261. http://doi.org/10.1359/jbmr.1997.12.8.1253

381 Kwan Tat, S., Padrines, M., Théoleyre, S., Heymann, D., \& Fortun, Y. (2004). IL-

3826 , RANKL, TNF-alpha/IL-1: interrelations in bone resorption

383 pathophysiology. Cytokine \& Growth Factor Reviews, 15(1), 49-60.

384 Maddalozzo, G. F., \& Snow, C. M. (2000). High intensity resistance training:

385 effects on bone in older men and women. Calcified Tissue International, $386 \quad 66(6), 399-404$.

387 Metcalfe, R. S., Babraj, J. A., Fawkner, S. G., \& Vollaard, N. B. J. (2011).

388 Towards the minimal amount of exercise for improving metabolic health:

389 beneficial effects of reduced-exertion high-intensity interval training.

$390 \quad$ European Journal of Applied Physiology, 112(7), 2767-2775.

391 http://doi.org/10.1007/s00421-011-2254-z

392 Metcalfe, R. S., Tardif, N., Thompson, D., \& Vollaard, N. B. J. (2016). Changes

393 in aerobic capacity and glycaemic control in response to reduced-exertion

394 high-intensity interval training (REHIT) are not different between sedentary

395 men and women. Applied Physiology, Nutrition, and Metabolism, 41(11), 
1117-1123. http://doi.org/10.1139/apnm-2016-0253

Mezil, Y. A., Allison, D., Kish, K., Ditor, D., Ward, W. E., Tsiani, E., \& Klentrou, P. (2015). Response of Bone Turnover Markers and Cytokines to High-Intensity Low-Impact Exercise. Medicine \& Science in Sports \& Exercise, 47(7), 1495-1502. http://doi.org/10.1249/MSS.0000000000000555

Olmedillas, H., González-Agüero, A., Moreno, L. A., Casajus, J. A., \& VicenteRodríguez, G. (2012). Cycling and bone health: a systematic review. BMC Medicine, 10(1), 168. http://doi.org/10.1186/1741-7015-10-168

Ruffino, J. S., Songsorn, P., Haggett, M., Edmonds, D., Robinson, A. M.,

Scott, A., Khan, K. M., Duronio, V., \& Hart, D. A. (2008). Mechanotransduction in human bone: in vitro cellular physiology that underpins bone changes with exercise. Sports Medicine (Auckland, N.Z.), 38(2), 139-160.

414 Shing, C. M., Webb, J. J., Driller, M. W., Williams, A. D., \& Fell, J. W. (2013). Circulating Adiponectin Concentration and Body Composition Are Altered in Response to High-Intensity Interval Training. The Journal of Strength \& Conditioning Research, 27(8), 2213-2218. http://doi.org/10.1519/JSC.0b013e31827e1644

Sim, A. Y., Wallman, K. E., Fairchild, T. J., \& Guelfi, K. J. (2013). High-intensity intermittent exercise attenuates ad-libitum energy intake. International 
422 Sim, A. Y., Wallman, K. E., Fairchild, T. J., \& Guelfi, K. J. (2015). Effects of

423 High-Intensity Intermittent Exercise Training on Appetite Regulation.

$424 \quad$ Medicine \& Science in Sports \& Exercise, 47(11), 2441-2449.

$425 \quad$ http://doi.org/10.1249/MSS.0000000000000687

426 Skerry, T. M. (2006). One mechanostat or many? Modifications of the site-

427 specific response of bone to mechanical loading by nature and nurture.

$428 \quad$ Journal of Musculoskeletal \& Neuronal Interactions, 6(2), 122-127.

429 Smith, A. E., Walter, A. A., Graef, J. L., Kendall, K. L., Moon, J. R., Lockwood,

430 C. M., et al. (2009). Effects of $\beta$-alanine supplementation and high-intensity

431 interval training on endurance performance and body composition in men; a

432 double-blind trial. Journal of the International Society of Sports Nutrition,

$433 \quad 6(1), 5-9 . \mathrm{http}: / /$ doi.org/10.1186/1550-2783-6-5

434 Strasser, B. (2012). Physical activity in obesity and metabolic syndrome. Annals

435 of the New York Academy of Sciences, 1281(1), 141-159.

$436 \quad$ http://doi.org/10.1111/j.1749-6632.2012.06785.x

437 Terada, T., Friesen, A., Chahal, B. S., Bell, G. J., McCargar, L. J., \& Boulé, N. G.

438 (2013). Feasibility and preliminary efficacy of high intensity interval training

439 in type 2 diabetes. Diabetes Research and Clinical Practice, 99(2), 120-129.

$440 \quad$ http://doi.org/10.1016/j.diabres.2012.10.019

441 Vainionpää, A., Korpelainen, R., Leppäluoto, J., \& Jämsä, T. (2004). Effects of

442 high-impact exercise on bone mineral density: a randomized controlled trial in

443 premenopausal women. Osteoporosis International, 16(2), 191-197.

$444 \quad$ http://doi.org/10.1007/s00198-004-1659-5

445 Verney, J., Kadi, F., Saafi, M. A., Piehl-Aulin, K., \& Denis, C. (2006). Combined 
$446 \quad$ lower body endurance and upper body resistance training improves

447 performance and health parameters in healthy active elderly. European

$448 \quad$ Journal of Applied Physiology, 97(3), 288-297.

$449 \quad$ http://doi.org/10.1007/s00421-006-0175-z

450 Vickers, A. J. (2001). The use of percentage change from baseline as an outcome

451 in a controlled trial is statistically inefficient: a simulation study. BMC

$452 \quad$ Medical Research Methodology, 1, 6.

453 Wang, Z. M., R N Pierson, J., \& Heymsfield, S. B. (1992). The five-level model:

454 a new approach to organizing body-composition research. The American

$455 \quad$ Journal of Clinical Nutrition, 56(1), 19-28.

456 Weston, K. S., Wisløff, U., \& Coombes, J. S. (2014). High-intensity interval

457 training in patients with lifestyle-induced cardiometabolic disease: a

458 systematic review and meta-analysis. British Journal of Sports Medicine,

459 48(16), 1227-1234. http://doi.org/10.1136/bjsports-2013-092576

460 
Table 1. Changes in Body Composition

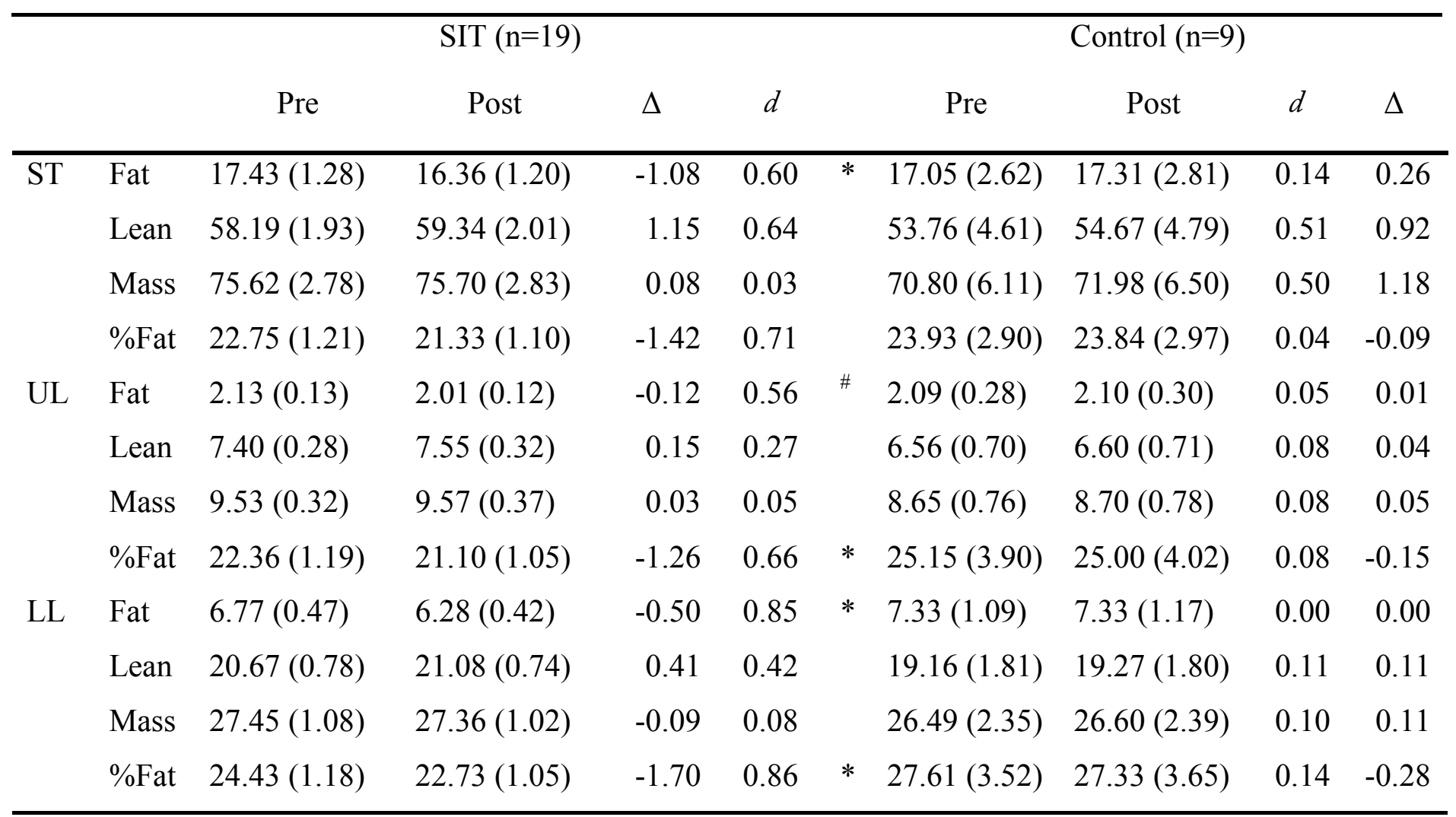

All values shown are mean (SE). All units are kg with the exception of \% Fat. * denotes difference from control group $\left({ }^{*} \mathrm{p}<0.05\right) . \Delta$; Change from Baseline, $d$; Cohens D SIT; Sprint Interval Training, LL; Lowerlimbs, ST; Sub-total, UL; Upper-limbs LL; Lower-limbs. 
Table 2 Changes in Bone Mineral Content, Density and Area measured by DXA following 6 weeks SIT.

\begin{tabular}{|c|c|c|c|c|c|c|c|c|c|c|}
\hline & \multicolumn{4}{|c|}{ SIT } & & \multicolumn{4}{|c|}{ CONTROL } \\
\hline & & Pre & Post & $\Delta$ & $d$ & & Pre & Post & $\Delta$ & $d$ \\
\hline \multirow[t]{3}{*}{ Total LS } & BMA & $71.30(0.92)$ & $72.66(0.84)$ & 1.36 & 0.74 & & $66.04(0.77)$ & $67.18(0.82)$ & 1.14 & 0.54 \\
\hline & $\mathrm{BMC}$ & $83.99(2.45)$ & $86.38(2.82)$ & 2.39 & 0.45 & & $69.40(1.55)$ & $70.10(1.62)$ & 0.50 & 0.44 \\
\hline & BMD & $1.16(0.02)$ & $1.17(0.03)$ & 0.01 & 0.12 & & $1.05(0.02)$ & $1.04(0.02)$ & -0.01 & 0.11 \\
\hline \multirow[t]{3}{*}{ Total PF } & BMA & $44.16(0.72)$ & $46.17(0.69)$ & 2.01 & 1.10 & \# & $43.13(0.69)$ & $43.26(0.67)$ & 0.13 & 0.09 \\
\hline & $\mathrm{BMC}$ & $51.84(1.68)$ & $54.35(1.58)$ & 2.51 & 0.88 & $\#$ & $47.71(1.47)$ & $47.59(1.42)$ & -0.12 & 0.02 \\
\hline & $\mathrm{BMD}$ & $1.15(0.02)$ & $1.16(0.02)$ & 0.01 & 0.32 & & $1.09(0.02)$ & $1.09(0.02)$ & 0.00 & 0.10 \\
\hline \multirow[t]{3}{*}{$\mathrm{FN}$} & BMA & $6.01(0.06)$ & $5.99(0.05)$ & -0.02 & 0.08 & & $5.98(0.07)$ & $5.73(0.06)$ & -0.25 & 0.48 \\
\hline & $\mathrm{BMC}$ & $6.28(0.18)$ & $6.33(0.16)$ & 0.05 & 0.02 & & $5.80(0.17)$ & $5.46(0.15)$ & -0.34 & 0.59 \\
\hline & BMD & $1.03(0.02)$ & $1.05(0.02)$ & 0.02 & 0.24 & $\#$ & $0.96(0.02)$ & $0.94(0.02)$ & -0.02 & 0.26 \\
\hline \multirow[t]{3}{*}{ WT } & BMA & $1.17(0.01)$ & $1.11(0.01)$ & -0.06 & 0.91 & & $1.18(0.01)$ & $1.18(0.01)$ & 0.00 & 0.00 \\
\hline & $\mathrm{BMC}$ & $1.09(0.03)$ & $1.06(0.03)$ & -0.03 & 0.33 & & $1.04(0.04)$ & $1.02(0.04)$ & -0.02 & 0.36 \\
\hline & $\mathrm{BMD}$ & $0.94(0.02)$ & $0.96(0.03)$ & 0.02 & 0.42 & & $0.87(0.03)$ & $0.86(0.03)$ & -0.01 & 0.29 \\
\hline
\end{tabular}

Units: BMA $\left(\mathrm{cm}^{2}\right)$, BMC $(\mathrm{g}), \mathrm{BMD}\left(\mathrm{g}^{\bullet} \mathrm{cm}^{-2}\right)$. \#; denotes difference from control group $(\mathrm{p}<0.1)$. $\Delta$; Change from

Baseline, d; Cohen's d FN; Femoral Neck, SIT; Sprint Interval Training, LS: Lumbar Spine, PF; Proximal Femur,

WT: Wards Triangle 


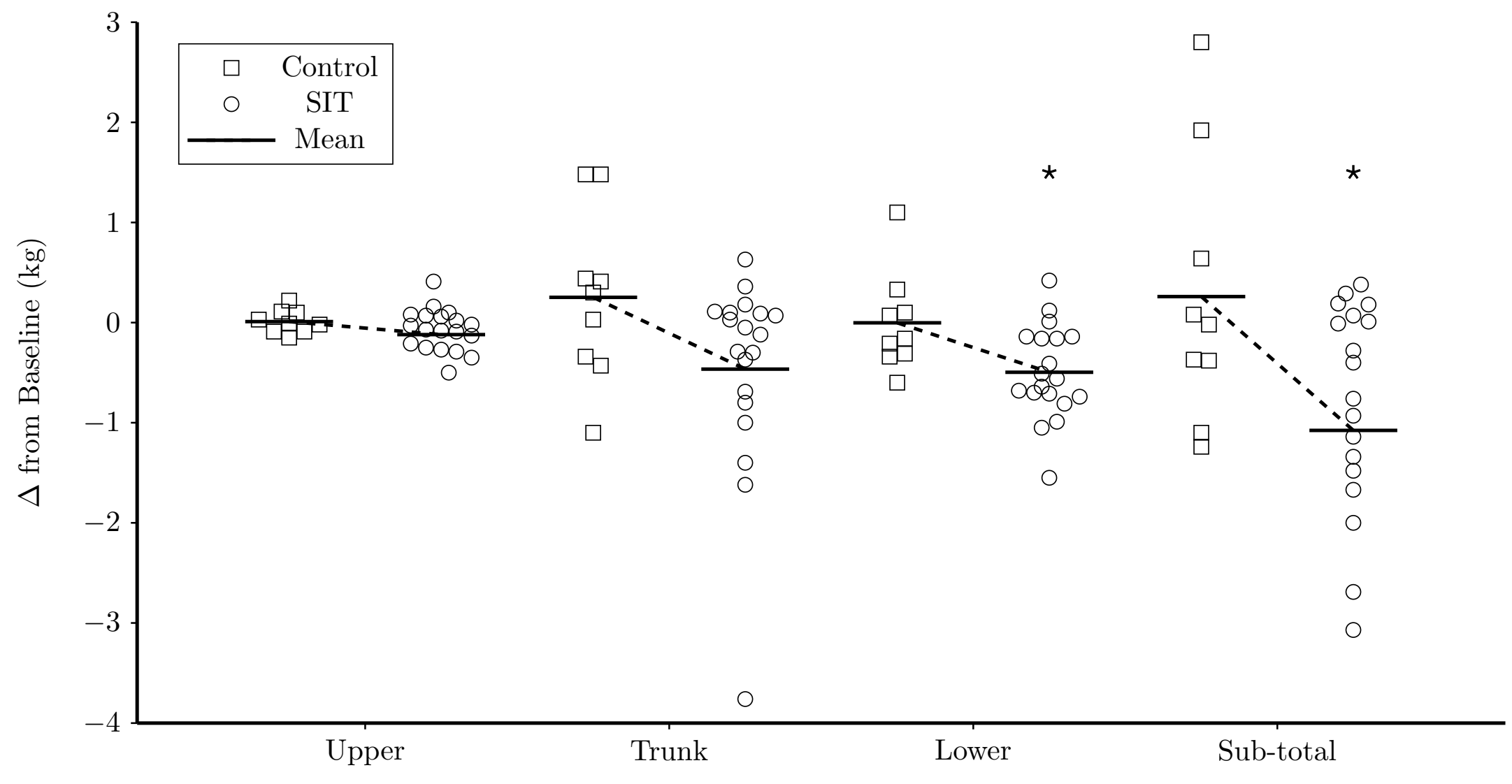

Figure 1 Effect of 6-weeks of sprint interval training (SIT) or no training (Control) on change in fat mass (kg) of the upper limbs, trunk, lower limbs and sub-total regions measured by DXA. Circles/squares show individual change and horizontal bars show mean 


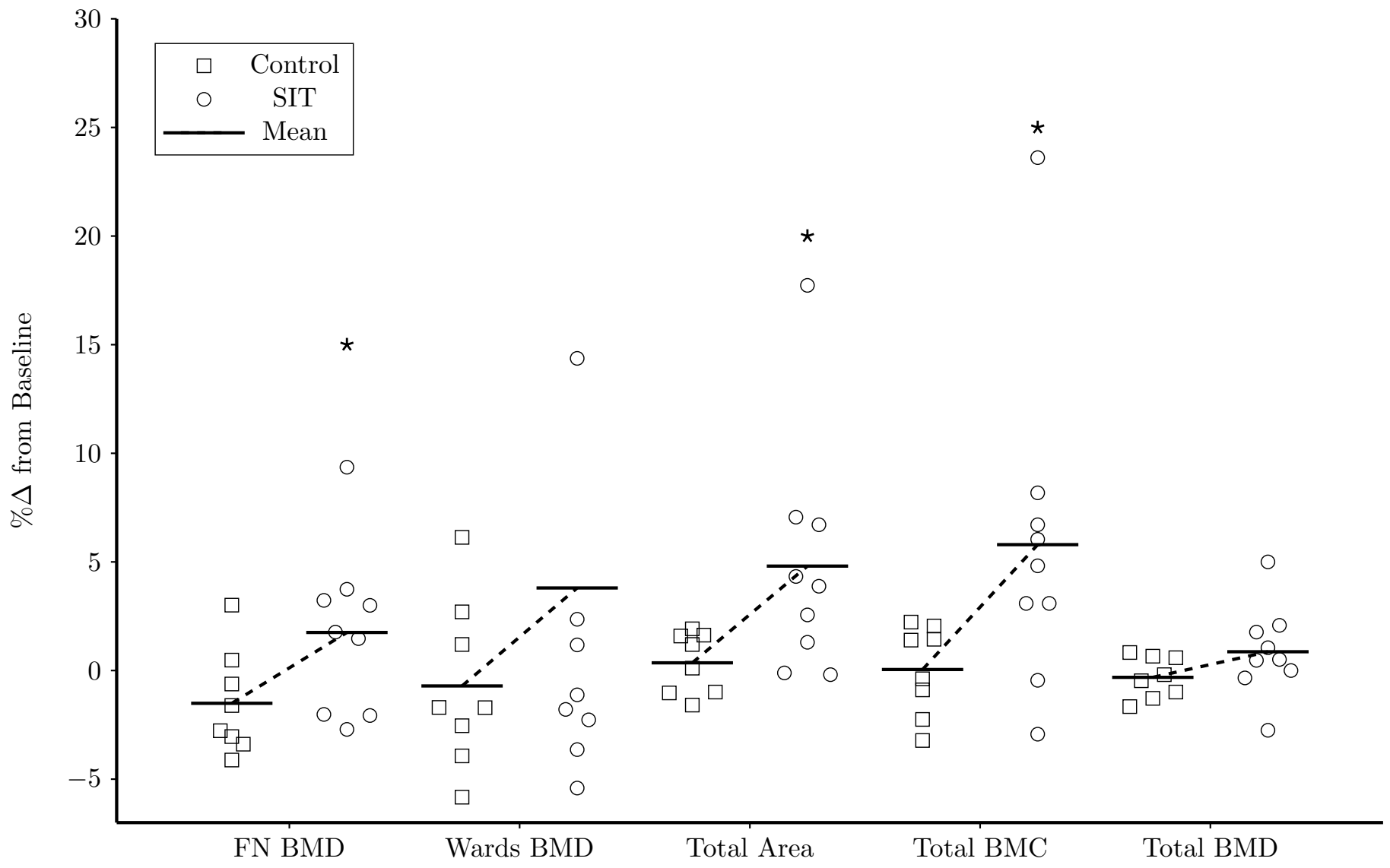

Figure 2 Percentage change from baseline in Total Proximal Femur (Total) bone mineral density (BMD), bone mineral content (BMC), and Area as well as Femoral Neck (FN) and Wards triangle (Wards) BMD following 6 weeks SIT. Circles/squares show individual change and horizontal bars show mean group change from baseline. * denotes different from control group $(p<0.1)$. 